OPEN ACCESS

Edited by:

Min Tang,

University of Applied Management, Germany

Reviewed by: Boris Forthmann, University of Münster, Germany

Baptiste Barbot,

Yale University, United States

*Correspondence:

Sergio Agnoli

sergio.agnoli@unibo.it

Specialty section:

This article was submitted to

Cognition,

a section of the journa

Frontiers in Psychology

Received: 31 January 2019 Accepted: 02 August 2019

Published: 21 August 2019

Citation:

Agnoli S, Mastria S, Kirsch C and Corazza GE (2019) Creativity in the Advertisement Domain:

The Role of Experience on Creative Achievement.

Front. Psychol. 10:1899.

doi: 10.3389/fpsyg.2019.01899

\section{Creativity in the Advertisement Domain: The Role of Experience on Creative Achievement}

\author{
Sergio Agnoli ${ }^{1 \star}$, Serena Mastria ${ }^{1,2}$, Christiane Kirsch ${ }^{1}$ and Giovanni Emanuele Corazza ${ }^{1,2}$ \\ ${ }^{7}$ Marconi Institute for Creativity, MIC, Sasso Marconi, Italy, ${ }^{2}$ Department of Electrical, Electronic, and Information Engineering \\ "Guglielmo Marconi", University of Bologna, Bologna, Italy
}

The creativity of an advertisement campaign is one of the most relevant predictors of its success. Past research has highlighted the relevance of domain-specific experience in enhancing creativity, but the results are controversial. We explored the role of work experience, in terms of number of years spent in the advertisement domain, in various forms of creativity expressed within this specific working domain. We hypothesized a mediator role of experience in the relationship between the individual's creative potential, as measured through a series of divergent thinking tasks, and creative achievement in the advertisement domain. Moreover, considering the importance of personality in creative achievement, we also explored the influence of the openness-to-experience on advertisers' creative achievement. A range of measures assessing creative achievement, openness, and divergent thinking abilities in terms of fluency and originality were administered to a group of professionals in the advertisement domain. The results demonstrate a crucial role for experience in the connection between originality and creative achievement. Moreover, our findings extend previous studies by showing that fluency and openness are significant predictors of creative achievement in the advertisement environment. These results emphasize the importance of canalizing the advertiser's divergent thinking abilities through appropriate routes provided by working experience, raising important implications for future explorations of domain-specific creative achievement within an individual differences framework. Final indications for future developments are provided, with a special emphasis on the replication of these findings in various work domains and in various cultural contexts.

Keywords: creative achievement, advertisement, experience, divergent thinking, openness

\section{INTRODUCTION}

\section{Creativity in the Advertising Working Environment}

Creativity is unquestionably at the core of the professional advertising domain. The planning and the execution of optimal creative strategies are crucial for the development of effective advertising (El-Murad and West, 2004; Sasser and Koslow, 2008a, 2012; Nyilasy and Reid, 2009). To be considered creative in the advertising literature, a product should be both novel 
and relevant or appropriate to be able to enhance purchase intentions for the associated brand (Koslow et al., 2003; Smith and Yang, 2004). Although novelty can refer to something unusual or different in some way, relevance can be thought of as a stimulus property that is meaningful to the consumer (Ang and Low, 2000; Smith and Yang, 2004). This definition is totally in line with the psychological literature's definition of creativity (Runco and Jaeger, 2012; Corazza, 2016; Corazza and Agnoli, 2016), which considers originality and effectiveness as the two distinctive elements of a creative idea. Extensive research exists on advertisers' creative success and creative process, showing specific components and determinants of advertising creativity (e.g., Smith et al., 2007; Sasser and Koslow, 2008b). From this literature, the advertisement working environment emerges as an exceptional case study to explore outstanding creative behaviors. On the one hand, advertisers need to produce novel, useful, and surprising campaigns, which is consistent with the classical notion of novelty, usefulness, and surprise as constituents of a creative idea (Bruner, 1962; Simonton, 2012, 2018). On the other hand, advertisers must select the most meaningful messages to immediately stimulate the costumers' taste. The acquisition of experience in the development of solutions balanced between novelty, relevance, and surprise can be considered as a fundamental requirement in the advertising domain ${ }^{1}$. Therefore, in the present work we were specifically interested in exploring the predictors of various forms of creativity within the advertisement working environment, with a special emphasis on the role of work experience.

\section{The Role of Experience in Creativity}

The importance of domain-specific experience in the analysis of individual creative potential has been highlighted in previous research (Amabile, 1996; Kilgour and Koslow, 2009; Sasser and Koslow, 2012). Studies investigating the role of experience in creative ideation, however, show controversial results. A number of studies suggested that experience is a conditio sine qua non to come up with a novel and useful idea in professional fields (e.g., Simonton, 2003; Tiwana and McLean, 2005; Taylor and Greve, 2006), but other researchers have shown that high levels of experience may at some point limit the ability to generate creative ideas (Adelson, 1984; Frensch and Sternberg, 1989; Wiley, 1998; Audia and Goncalo, 2007). This limitation could be due to experts' particular mindset, in which reinforced associations and efficient retrieval processes lead to functional fixedness (Wiley, 1998; Schilling, 2005). Despite these discrepancies, both lines of research showed an association between experience and the probability of achievement in creative activities. Even if past research showed that experience could increase an individual's creative abilities, one can alternately hypothesize that creative abilities, particularly the ability to produce original ideas, can be considered prerequisites to working in a highly creative environment, such as the advertisement working domain. Consequently, we expected that

${ }^{1}$ It is worth highlighting that domain is treated here as a knowledge context related to a specific working environment and experience, not as the knowledge sphere related to a specific cognitive function. individual's creative abilities could predict the number of years of experience in the advertisement environment. In other words, a higher level of creative skills could be associated with longer experience in an advertising job.

\section{The Current Study: Aims and Hypotheses}

Therefore, the aim of the present study was to explore creative achievement in a group of professionals in advertising, focusing on the predictive role of domain-specific experience and ideational ability, as measured through divergent thinking (DT). Here, experience refers to the conventional measure of the number of years spent in the professional advertising working domain. The creative process entails the use of several cognitive/ emotional abilities (Mumford et al., 1991; Sternberg and Lubart, 1996; Lubart, 2001), metacognition, and emotional intelligence (Agnoli et al., 2019; Sánchez-Ruiz et al., 2011), as demonstrated in the advertisement domain (Sasser and Koslow, 2008b). However, we focus on divergent thinking abilities because the skill of generating novel and relevant brand/messages implies the ability to ideate many alternative solutions as well as original and appropriate ideas (Smith and Yang, 2004). Moreover, divergent thinking has been found to be a meaningful indicator of creative potential (Runco and Acar, 2012). Here, in fact, divergent thinking has been assessed in terms of ideational fluency, that is, the quantity of ideas, and originality, that is, the quality of ideas (e.g., Guilford, 1968; Runco and Albert, 1986; Forthmann et al., 2017) produced in a series of divergent thinking tasks. Specifically, in order to account for the multifold nature of divergent thinking, we used a combination of divergent thinking tasks. Creative achievement was assessed through a widely used measurement instrument, the Creative Activity and Accomplishment Checklist (CAAC; Holland, 1960; Wallach and Wing, 1969; Hocevar, 1981; Runco et al., 1990; Milgram and Hong, 1999; Paek et al., 2016). We therefore adopted a psychometric approach to analyze creative achievement by assessing, via the CAAC, the frequency with which professionals in advertising performed a series of creative activities in their working domain. We focused on achievement in three forms of creativity: (1) scientific creative achievement and (2) artistic creative achievement as the two most-explored forms of domainspecific creativity in the psychological research (e.g., Feist, 1998; Batey and Furnham, 2006) and (3) everyday creative achievement as a domain-general form of creativity. In the present study, we required participants to report how frequently they performed scientific, artistic, and everyday creative activities exclusively within the advertisement working context. We intended to use this measurement approach to analyze, within an advertisement working environment, the predictive role of ideational abilities and experience on some of the most explored forms of creative achievement in the psychological creativity research.

Based on results showing that minimal experience is necessary to ensure a high level of creative success (e.g., Simonton, 1988, 2003), we expected that the years spent in the advertisement working domain could predict creative achievement in a group of advertising professionals. This expectation was in line with past research that highlighted various creative 
behaviors in experts and novices in the advertisement domain (e.g., Griffin, 2008). For instance, Kilgour and Koslow (2009) found differences between novices and experts, suggesting that expert creatives had embodied creative thinking techniques to overcome functional fixedness. Moreover, we hypothesized that the ability to generate ideas through divergent thinking (i.e., an individual's creative potential; Runco and Acar, 2012) was necessary to work in the advertisement domain, and we explored whether originality and fluency scores in a series of divergent thinking tasks could predict the years spent by professionals in the advertisement domain. More importantly for the aim of the present work, we assumed that the influence of divergent thinking on advertisers' creative achievement was mediated by the individual's experience in the professional domain. We explored an indirect effect of divergent thinking on creative achievement through a mediation analysis, hypothesizing that through experience divergent thinking could have a positive influence on creative success in a group of professionals in advertising. In particular, we hypothesized that experience should help individuals working in the advertisement domain learn the rules, the best practices, and the most efficient strategies to exploit their creative potential and succeed in creative activities that occur in this highly competitive context. Past research seems to support this hypothesis, specifically demonstrating that individuals learn with experience how to increase control over their creative abilities (e.g., refining their modality to select ideas, i.e., their convergent-orientated strategic thinking; Kilgour and Koslow, 2009). The direct and indirect effects (via experience) of fluency and originality on creative achievement were therefore explored. We also considered the cross-correlation between the two variables, given the highly complex relationship characterizing these two divergent thinking indexes (Forthmann et al., 2018).

Among the individual differences that can influence creative achievement, personality plays an important role (Amabile, 1983; Batey and Furnham, 2006) that, in conjunction with the influence of divergent thinking abilities, helps explain a significant portion of the individual's creative potential (Jauk et al., 2014). Many studies have investigated the relationship between creativity and personality (Costa and McCrae, 1992; Feist, 1998), identifying openness to experience as a personality dimension that is highly associated with creativity in the Big Five model of personality, which can explain, in particular, the highest portion of variance due to personality in the prediction of creative behavior (Feist, 1998; Batey and Furnham, 2006; Silvia et al., 2009; Kaufman, 2013; Li et al., 2014). Openness to experience captures the extent to which individuals are imaginative, open-minded, and curious, and it is considered the most significant predictor within the personality domain of divergent thinking performance in terms of originality and fluency (McCrae, 1987; Agnoli et al., 2015; Puryear et al., 2017). Furthermore, openness seems to relate to creative achievement in a wide range of domains and contexts (Feist, 1998; Kaufman, 2013; Agnoli et al., 2018). To control for the potential influence of inter-individual differences in terms of openness, we explored whether openness may both directly and indirectly influence creative achievement in a group of advertising professionals (e.g., Baer and Oldham, 2006; Leung et al., 2008; Jauk et al., 2014). Assuming that the creative achievement of advertisers would be also influenced by the openness-to-experience personality trait, we indeed controlled the effect of divergent thinking abilities and experience on creative achievement for the individual differences in this personality trait.

\section{MATERIALS AND METHODS}

\section{Participants}

Sixty-nine professionals (53 men, 16 women, $M_{\text {Age }}=32.91$, $\mathrm{SD}=8.06$, age range from 21 to 50 years) employed in a large advertising company in London (UK) agreed to participate in the study. The sample included professionals from the following working macro-categories: advertising (17), copywriting (7), artistic direction (28), digital/social advertising (7), account planning (7), and innovation and technology (3). Participants' experience was measured as the number of working years spent in the advertisement working domain $\left(M_{\text {years }}=9.90\right.$, $\mathrm{SD}=8.00$, range from 0 to 29 years). Participants completed a subset of tests derived from a larger test battery to assess creative behavior (Agnoli et al., 2016), as described in the following.

\section{Self-Report Measures}

\section{Creative Activity and Accomplishment Checklist}

Creative achievement was measured by the CAAC, which is part of the Runco Creativity Assessment Battery. The CAAC is one of the most widely used measures for assessing creative achievement, and its reliability and validity have been demonstrated in a number of past studies (Holland, 1960; Wallach and Wing, 1969; Hocevar, 1981; Runco et al., 1990; Milgram and Hong, 1999; Paek et al., 2016; Agnoli et al., 2018). The present study used a short 45 -item version of the instrument that referred to the artistic, scientific, and everyday creative domains. An example item for artistic creative achievement was: "How many times, or how often, have you received an award for an artistic accomplishment?" An example item for the scientific creative achievement was: "How many times, or how often, have you solved statistical/ mathematical problems with a computer?" An example item for the everyday creative achievement was: "How many times, or how often, have you decorated some place for a party or special event?" We were interested in the creative achievement of workers with regard to their profession, so each item referred to an activity performed in one of the three domains (artistic, scientific, or everyday) within their working environment. Participants in particular were prompted to consider each item from all three domains likely to be experienced as part of their work, indicating how frequently they performed each activity during their work. The responses were given on a 4-point Likert scale: A (Never did this), B (Did this once or twice), C (three to five times), and D (More than five times). For each item, participants were instructed to choose the response $(\mathrm{A}-\mathrm{D})$ that best described the frequency with which 
they performed activity within their working environment, with these specific instructions: "This is an inventory, not a test. The inventory is simply a list of activities and accomplishments in various fields. Your task is to circle the response (A-D) that best describes how frequently you performed the activity in your work. We would like to know how often you have done each of the activities at work. Be sure to answer every question, and do not worry about duplicate or similar items. How many times, or how often, have you .... All CAAC subscales showed a good reliability: artistic creative achievement at work, $\alpha=0.83$; scientific creative achievement at work, $\alpha=0.81$; and everyday creative achievement at work, $\alpha=0.81$. A total creative achievement score was derived by averaging scores from the domain-specific forms of creative achievement (art and science) and from the domain-general form of creative achievement (everyday), obtaining a global score for each participant for the creative achievements within the working domain, which was then used in the statistical analyses. Reliability for the global score was good: ICC $=0.67$.

\section{Ten-Item Personality Inventory}

The Big Five personality was assessed by a 10 -item short version of the Big Five Inventory, the Ten-Item Personality Inventory (TIPI; Gosling et al., 2003). The Big Five model includes Openness to Experience, Conscientiousness, Extraversion, Agreeableness, and Emotional Stability (Costa and McCrae, 1989, 1992). The TIPI scale was shown to be a reliable tool for rapidly assessing the Big Five traits, and its validity has previously been established (for example, with good test-retest reliability; Gosling et al., 2003). In the TIPI scale, every item consists of two adjectives corresponding to the positive and negative extremes of the corresponding Big Five dimension. Each item starts with the description "I see myself as:" and responses are given on a 7-point scale, ranging from 1 (strongly disagree) to 7 (strongly agree). Participants were asked to indicate the extent to which each pair of opposite traits applied to them, even if one extreme applied more strongly than the other. The purpose of the present study was to investigate whether the openness trait influences creative achievement in the advertising environment, so we included only openness to experience scores in the statistical analyses.

\section{Divergent Thinking Tasks}

Advertisers' divergent thinking abilities were assessed via three tests: the Titles task (Guilford, 1968), the Figures task (Runco and Albert, 1985), and the Realistic Problems task (Runco et al., 2005), which are part of the Runco Creativity Assessment Battery. During these three tasks, participants were asked to generate the maximum number of alternative ideas while enjoying themselves (for a total duration of 9 min per task-3 min per title/figure/problem), and they were reassured that their responses would not be graded. In the Titles task, participants were asked to produce original and appropriate alternative titles for two well-known books and for a movie (Agnoli et al., 2016). In the Figures task, participants were asked to list a maximum number of alternative interpretations for each of three abstract black-and-white line drawings (Wallach and Kogan, 1965; Runco and Albert, 1985). Finally, the Realistic Problems task (Runco et al., 2005) included open-ended questions involving real-life situations that participants might have already experienced. Research provided evidence that Realistic Problems tasks are valid measures of divergent thinking (Runco et al., 2006). The realistic aspect of these problems makes individuals more engaged, as they have enough information derived from experience to solve these problems, which consequently leads to higher ideational fluency rates. To assess individual differences in originality, the scoring procedure proposed by Wilson et al. (1953) was used in the current study. For each task, responses were scored from 1 (not at all original) to 5 (highly original) by two expert judges with an expertise in creativity research and originality coding. The judges were required to score items as uncommon, remote, and clever. The judges were aware that including these three criteria into their evaluation implied that strength on one criterion could balance out weakness on another criterion. The inter-rater reliability, calculated on the total number of responses, was good (Cohen's $\kappa$ ranged from 0.78 to 0.91 ). For large discrepancies between ratings, the judges were asked to review their responses and assign a score by consensus. Raw originality and fluency scores in the three tasks were standardized (z-transformation). The total scores for originality and fluency were derived for each participant by averaging the originality and fluency $\mathrm{z}$-scores in the three divergent thinking tasks altogether. Participants generated a total of 5,333 responses for the three divergent thinking tasks.

\section{Data Analysis}

A path analysis was performed in Mplus 7.4 (Muthén and Muthén, 2015) in order to test our hypotheses and, in particular, the mediation role of experience in the relationship of divergent thinking and openness with creative achievement. Given the typical highly skewed and overdispersed outcomes of creative achievements (for an overview on this topic, see Silvia et al., 2012) and the relatively small sample size, a Bayesian estimator was used to avoid relying on a large-sample theory and normal distribution assumptions, thus producing more accurate estimates with smaller samples (Lee and Song, 2004). A Bayesian analysis allows us to use posterior predictive $p$ to evaluate the model fit (Kaplan and Depaoli, 2012; Muthén and Asparouhov, 2012). The rationale for posterior predictive model checking is to explore whether the data replicated through the model match the observed data (e.g., Muthén and Asparouhov, 2012). Specifically, posterior predictive model checking samples the posterior estimates of model parameters and uses these samples to generate a data set that has the same size as the observed data set, producing a posterior distribution. To report the statistical uncertainty about the population distribution, a point estimate alone is not sufficient and an estimate in the form of an interval is usually preferred. Frequentist approaches call such an interval a confidence interval, Bayesian approaches call it a credible interval, which is conventionally set at a fixed value of $95 \%$. Credibility intervals are usually complemented 
by a full posterior distribution for the effect size measure under study, which can be summarized by measures of central tendency (e.g., median, mean, or mode) and measures of uncertainty (e.g., variance or standard deviation). The probability of the observed data set and the probability of the generated data set are then estimated with chi-square tests (Stenling et al., 2015). The model fit with the Bayesian estimator is usually determined in two ways. In Bayesian posterior predictive checking, a 95\% confidence interval with a negative lower limit is considered one indicator of a good model fit. In posterior predictive $p$, low values $(<0.05)$ based on the usual chi-square test of $\mathrm{H}_{0}$ against $\mathrm{H}_{1}$ indicate a poor fit (Muthén and Asparouhov, 2012). In particular, a well-fitting model should have a posterior predictive $p$ around 0.5 (Muthén and Asparouhov, 2012).

\section{RESULTS}

Descriptive statistics and correlations among the variables are depicted in Table 1. A positive correlation was found between creative achievement and fluency $(r=0.35, p<0.01)$ and creative achievement and openness $(r=0.28, p=0.019)$. Moreover, originality was positively related to experience $(r=0.28, p=0.019)$, openness $(r=0.24, p=0.051)$, and fluency $(r=0.26, p=0.033)$, supporting our hypothesis of an inter-relation between divergent thinking and experience and between the two divergent thinking indexes.
The Bayesian fit statistics indicated that the tested model provided a good fit to the data: Posterior Predictive Checking $=95 \%$ $\mathrm{CI}=[-19.153,20.591]$ and posterior predictive $p=0.667$. As shown in Figure 1, the results indicated that originality was positively related to experience, $\beta=0.259$, posterior $\mathrm{SD}=0.132$, $95 \% \mathrm{CI}=[0.014,0.476]$, and that experience was a significant predictor of creative achievement, $\beta=0.346$, posterior $\mathrm{SD}=0.111$, $95 \% \mathrm{CI}=[0.150,0.557]$. Moreover, the total direct effect of originality on creative achievement emerged as not significant, $\beta=-0.169$, posterior $\mathrm{SD}=0.108,95 \% \mathrm{CI}=[-0.410,0.015]$. However, a specific indirect effect of originality on creative achievement emerged through experience, $\beta=0.081$, posterior $\mathrm{SD}=0.062,95 \% \mathrm{CI}=[0.005,0.215]$. In addition, the results revealed that fluency positively predicted creative achievement, $\beta=0.425$, posterior $\mathrm{SD}=0.119,95 \% \mathrm{CI}=[0.173,0.614]$, but it was not mediated by the effect of experience, $\beta=0.001$, posterior $\mathrm{SD}=0.039,95 \% \mathrm{CI}=[-0.059,0.088]$, and there was indeed no relationship between fluency and experience, $\beta=0.003$, posterior $\mathrm{SD}=0.116,95 \% \mathrm{CI}=[-0.202,0.224]$. Similarly, the results showed that openness positively predicted creative achievement, $\beta=0.213$, posterior $\mathrm{SD}=0.112,95 \% \mathrm{CI}=[0.037,0.458]$, but it was not mediated by the effect of experience, $\beta=0.033$, posterior $\mathrm{SD}=0.053,95 \% \mathrm{CI}=[-0.069,0.130]$, and there was indeed no relationship between openness and experience, $\beta=0.101$, posterior $\mathrm{SD}=0.130,95 \% \mathrm{CI}=[-0.167,0.352]$. Approximately $40 \%$ of the variance in creative achievement was accounted for by the model $\left(R^{2}=0.401\right)$.

TABLE 1 | Descriptive variables and correlations between experience, openness, fluency, originality, and creative achievement in advertisers.

\begin{tabular}{|c|c|c|c|c|c|c|c|c|c|}
\hline Variable & $M$ & SD & Min & Max & 1 & 2 & 3 & 4 & 5 \\
\hline 1. Experience & 9.90 & 8.00 & 0 & 29 & 1 & 0.14 & 0.07 & $0.28^{*}$ & 0.22 \\
\hline 2. Openness & 6.07 & 0.89 & 2.50 & 7.00 & & 1 & 0.19 & $0.24^{\star}$ & $0.28^{*}$ \\
\hline 3. Fluency & 8.48 & 2.56 & 4.33 & 19.56 & & & 1 & $0.26^{\star}$ & $0.35^{\star \star}$ \\
\hline 4. Originality & 1.65 & 0.24 & 1.22 & 2.40 & & & & 1 & -0.009 \\
\hline 5. Cr.Achiev. & 1.83 & 0.32 & 1.23 & 2.84 & & & & & 1 \\
\hline
\end{tabular}

$N=69$; originality and fluency scores are based on the average of the Titles, Figures, and Realistic Problem tasks; creative achievement (Cr. Achiev.) reflects the average score of the three artistic, scientific, and everyday CAAC dimensions (for details, see Method section). * $p<0.05 ;{ }^{* *} p<0.01$.

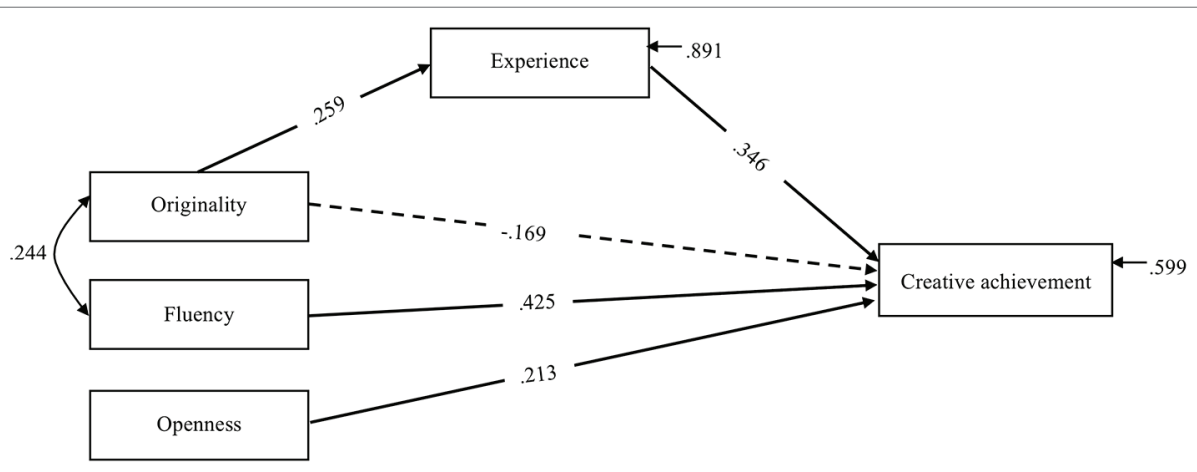

FIGURE 1 | Path analysis exploring the relationship between divergent thinking abilities (i.e., originality and fluency), openness, experience, and creative achievement in a group of professionals in advertisement. Creative achievement represents the total creative achievement score derived by averaging scores from the domain-specific forms of creativity (art and science) and the domain-general form of creativity (everyday) achieved within the advertisement working domain. Standardized coefficients are presented. Dotted lines represent not significant paths. 


\section{DISCUSSION}

The main aim of the present study was to explore creative achievement within a highly creative working domain, focusing on the relationship between domain-specific experience and divergent thinking abilities in predicting creative achievement while controlling for the effect of openness to experience. We specifically tested whether experience mediated the relation between divergent thinking and creative achievement inside an advertisement working environment. The rationale was that domain-experience, acquired over a number of years of work, might be crucial to exploit the individual creative potential in order to succeed in different forms of creativity within this extremely competitive and highly creative working environment.

The results confirmed the importance of experience for creative achievement, showing a direct influence of this variable on creative achievement and showing its significant influence on the relation between divergent thinking, viz. originality, and creative achievement. This result is totally in line with past research on the role of experience in the advertisement working domain, showing changes in strategies and working capacities as a consequence of the experience level within an advertising agency (Griffin, 2008; Kilgour and Koslow, 2009). Specifically, originality had a positive explanatory effect on creative achievement only via experience. The results revealed that experience affects the relation between divergent thinking and creative achievement, and that originality needs domain experience to have an indirect effect on creative achievement. It should be noted that, according to Hayes (2009), since there is no evidence that originality directly affects creative achievement, we cannot assume that experience mediates originality. Instead we can refer to an indirect effect of originality on creative achievement through the effect of experience. Therefore, on the basis of our results, we can state that (1) increasing originality is associated with an increase in the years spent in the advertisement working domain, making the ability to generate original ideas an important characteristic of professionals who have worked in this domain, and that (2) the increase in expertise can facilitate using this ideational ability to succeed in various forms of creative activities. It is worth highlighting that, in the present study, we did not measure the working achievements or successes obtained through creativity in the advertisement domain; we instead measured the level of achievement in scientific, artistic, and everyday creativity within this particular working environment, thus obtaining an aggregate index of an individual's success in a series of creative activities within this working domain. We specifically explored how experience in a highly creative working environment can help individuals use divergent thinking abilities to succeed in various forms of creativity in this particular domain.

One interpretation of our results is that increasing experience in the advertisement domain might help to retrieve a large amount of meaningful domain-related information and strategies that allow professionals to develop an ideational process suitable for achieving various forms of creativity. In other words, experience should help in controlling and in shaping the individual's ideational abilities by acquiring new and more sophisticated strategies to achieve creativity within this specific working environment. Among the strategies highlighted in past advertisement literature, we could, for example, hypothesize that experience promotes the refinement of strategic thinking-in other words, the thinking ability to select creative products by understanding how much an idea is on-strategy (Koslow et al., 2003; Kilgour and Koslow, 2009). This strategy is extremely useful in understanding the optimal level of originality needed to succeed in a particular advertisement campaign. By extension, this strategy could affect the success in various forms of creativity in this working domain, as measured in the present work. Previous studies have suggested that experience in a specific domain might be a disadvantage, as the mindset of people with experience may limit them to a knowledge area without creative solutions (Wiley, 1998). The case study of the advertisement environment explored in the current work shows that the relationship between experience and creativity seems more complex than this interpretation. Thus, even if experience results in functional fixedness during the ideation process (McCaffrey, 2012), our results showed that the thinkers' experience in their specific domain can somehow help in using their ideational ability to obtain creative success in various activities in that area.

Moreover, our findings confirmed and expanded previous studies (e.g., Jauk et al., 2014) by demonstrating that fluency is also a significant predictor of creative activities and achievements in the advertisement context. Specifically, fluency emerged from our analysis as the strongest predictor of creative achievement within this domain. In addition, this effect was totally independent from experience in this specific working environment. This result seems to be in line with the daily practice within advertisement, where the ability to produce many alternative ideas or to consider a problem under many different perspectives increases the likelihood of satisfying customers' needs. In this sense, we found evidence that ideational fluency is a requirement for success in various forms of creativity in the advertisement domain. Moreover, this finding corroborated the results by Vanden Bergh et al.s (1983) seminal work, which demonstrated the fundamental role of fluency for creative success in advertisement agencies.

Finally, we explored the influence of the openness personality trait on creative achievement. A number of previous studies found that individual differences in openness are highly related to creativity in the real world (Funder, 2001; Hu et al., 2011; Taki et al., 2013) and to creative achievement (Batey and Furnham, 2006; Agnoli et al., 2015, 2018). Our findings are in accordance with this literature, suggesting that openness to experience is a strong predictor of creative achievement in the advertising environment. The curiosity, aesthetic sensitivity, and imagination associated to openness are indeed personality characteristics that fit very well within advertisement work. It is reasonable to infer that openness to experience might play an important role in shaping advertisers' work 
by enhancing the probability of creative success within this working environment.

\section{Limitations and Future Directions}

The present work has two main limitations. The first is the study's relatively small sample size. Future studies should explore the relationship between ideational abilities, expertise, openness, and creative achievement in the advertisement domain with a higher number of employees in advertisement. Second, the present work's correlational nature cannot rule out alternative hypotheses. Even if our study provides a first indication for future research, only through a longitudinal design the causal role of experience implied by a mediation analysis could be explored. All data for the present study were collected at the same time point. This data collection approach represents a major limitation of this study with respect to (causal) inferences that can possibly be made from our analyses. Mediations that do not preserve the temporal ordering of all variables could produce biased estimates of model fit, relative to the same tests conducted with data that preserve the temporal ordering of all three variables (e.g., Cole and Maxwell, 2003; Maxwell and Cole, 2007). Moreover, it should be emphasized that measuring experience via time of employment could include some limitations because the duration of professional experience in a specific company does not inevitably result in equal results for all workers. Some individuals may improve their performance after a while, whereas others may take longer. Future studies could investigate experience as measured by the type and quality of particular experiences accumulated over time and its role on creative activities within the advertisement domain. In addition, directly examining the originality of advertisers' products may be important because in the present research we assessed originality by averaging scores from three divergent thinking tasks altogether (i.e., Titles task, Figures task, and Realistic Problems task). Moreover, controlling for other variables that may be correlated with experience, such as age or educational level, could elucidate our results. A further suggestion for future research could be to integrate and expand the present study's measurement approach to creative achievement. Whereas the current research uses a psychometric approach to assess some of the mostexplored forms of creative achievement in psychological literature, we believe that the generalizability of the present findings can be proven by exploring the working success obtained through the use of creative thinking in the advertisement domain by using and classifying indices of company success attributable to the creative work of individual workers (e.g., the assignment of industry awards). This approach could widen our results by analyzing the impact of the model tested in the present work on real-world working success.

Another consideration regards the methodologies for measuring creative achievement in psychological research. Most research on creative achievement uses measurement instruments that do not consider the context of where creative activities are performed. However, recent findings demonstrated that creative achievement in specific knowledge domains (e.g., science or art) is determined by different variables within different contexts (Paek et al., 2016; Agnoli et al., 2018). The context therefore takes a main role in defining the requirements for achievement in specific and general forms of creative activities. The present work represents the first exploration of the determinants of various forms of creative achievements within a specific working context. A further indication for future research is to continue this research line by expanding the current results outside of the advertisement work domain. It would be particularly important to understand whether these findings are a prerogative of the work context tested in the present study, or whether they can represent a reliable interpretative key to also understanding creative success in work contexts where creativity is not as central as it is in the advertisement domain.

Moreover, it is worth highlighting that creative achievement within a working context does not happen in a vacuum, and it should be always contextualized within societal and cultural norms. This could be done using a multilayer research approach aimed at exploring the mutual influence of cultural, contextual, knowledge-based, and individual levels on determining creative achievement. A final indication for future research could be exploring the role of various cultures in defining creative achievement within a work context by, for example, applying the present study outside of the English culture and over various European countries. This approach could clarify the inter-relationships between cultural and individual variables in defining specific forms of creative achievement in a highly creative work context, such as the advertisement domain.

\section{CONCLUSIONS}

Taken together and despite the above limitations, these findings have meaningful implications for the theoretical understanding of creative achievement in specific work contexts. We explicitly provided evidence that employees who are highly experienced, in terms of years spent in the advertisement domain, and openminded may reach high creative achievement inside their working environment and make better use of their divergent thinking abilities. However, we believe that much remains to be studied regarding the contributions of various types of domain knowledge, personality attitudes (e.g., creative self-beliefs), and cultural contexts on creativity to test the generalizability of the present findings.

\section{ETHICS STATEMENT}

This study was carried out in accordance with the recommendations of APA with written informed consent from all subjects in accordance with the Declaration of Helsinki. The protocol was approved by the Bioethics committee of the University of Bologna.

\section{AUTHOR CONTRIBUTIONS}

SA conceived the research idea, carried out the study, performed the statistical analyses, and wrote the manuscript. 
SM helped to develop the theoretical framework and to write the manuscript. CK contributed to sample preparation and helped in performing the statistical analyses. GC supervised the project and contributed to the interpretation of the results.

\section{FUNDING}

Paper supported by the CREAM project funded by the European Commission under Grant Agreement no 262022.

\section{REFERENCES}

Adelson, B. (1984). When novices surpass experts: the difficulty of a task may increase with expertise. J. Exp. Psychol. Learn. Mem. Cogn. 10, 483-495. doi: 10.1037/0278-7393.10.3.483

Agnoli, S., Corazza, G. E., and Runco, M. A. (2016). Estimating creativity with a multiple-measurement approach within scientific and artistic domains. Creat. Res. J. 28, 171-176. doi: 10.1080/10400419.2016.1162475

Agnoli, S., Franchin, L., Rubaltelli, E., and Corazza, G. E. (2015). An eyetracking analysis of irrelevance processing as moderator of openness and creative performance. Creat. Res. J. 27, 125-132. doi: 10.1080/10400419. 2015.1030304

Agnoli, S., Franchin, L., Rubaltelli, E., and Corazza, G. E. (2019). The emotionally intelligent use of attention and affective arousal under creative frustration and creative success. Personal. Individ. Differ. 142, 242-248. doi: 10.1016/j. paid.2018.04.041

Agnoli, S., Runco, M. A., Kirsch, C., and Corazza, G. E. (2018). The role of motivation in the prediction of creative achievement inside and outside of school environment. Think. Skills Creat. 28, 167-176. doi: 10.1016/j.tsc.2018.05.005

Amabile, T. M. (1983). The social psychology of creativity. New York: Springer Verlag.

Amabile, T. M. (1996). Creativity in context: Update to "the social psychology of creativity". (Boulder, CO: Westview).

Ang, S. H., and Low, S. Y. (2000). Exploring the dimensions of ad creativity. Psychol. Mark. 17, 835-854. doi: 10.1002/1520-6793(200010)17:10<835::AIDMAR1>3.0.CO;2-\#

Audia, P. G., and Goncalo, J. A. (2007). Success and creativity over time: a study of inventors in the hard disk drive industry. Manag. Sci. 53, 1-15. doi: $10.1287 / \mathrm{mnsc} .1060 .0593$

Baer, M., and Oldham, G. R. (2006). The curvilinear relation between experienced creative time pressure and creativity: moderating effects of openness to experience and support for creativity. J. Appl. Psychol. 91, 963-970. doi: 10.1037/0021-9010.91.4.963

Batey, M., and Furnham, A. (2006). Creativity, intelligence, and personality: a critical review of the scattered literature. Genet. Soc. Gen. Psychol. Monogr. 132, 355-429. doi: 10.3200/MONO.132.4.355-430

Bruner, J. S. (1962). "The conditions of creativity" in Contemporary approaches to creative thinking. eds. H. Gruber, G. Terrell and M. Wertheimer (New York, NY: Atherton), 1-30.

Cole, D. A., and Maxwell, S. E. (2003). Testing mediational models with longitudinal data: questions and tips in the use of structural equation modeling. J. Abnorm. Psychol. 112, 558-577. doi: 10.1037/0021-843X.112.4.558

Corazza, G. E. (2016). Potential originality and effectiveness: the dynamic definition of creativity. Creat. Res. J. 28, 258-267. doi: 10.1080/10400419. 2016.1195627

Corazza, G. E., and Agnoli, S. (2016). "On the path towards the science of creative thinking" in Multidisciplinary contributions to the science of creative thinking. eds. G. E. Corazza, and S. Agnoli (Singapore: Springer), 3-19.

Costa, P. T., and McCrae, R. R. (1989). NEO five-factor inventory (NEO-FFI). (Odessa, FL: Psychological Assessment Resources).

Costa, P. T., and McCrae, R. R. (1992). Four ways five factors are basic. Personal. Individ. Differ. 13, 653-665. doi: 10.1016/0191-8869(92)90236-I

El-Murad, J., and West, D. C. (2004). The definition and measurement of creativity: what do we know? J. Advert. Res. 44, 188-201. doi: 10.1017/ S0021849904040097
This publication reflects the views only of the authors, and the European Commission cannot be held responsible for any use which may be made of the information contained therein.

\section{ACKNOWLEDGMENTS}

The authors would like to acknowledge Pete Edwards and Simon Mutter for the fruitful discussion and helpful comments.

Feist, G. J. (1998). A meta-analysis of personality in scientific and artistic creativity. Personal. Soc. Psychol. Rev. 2, 290-309.

Forthmann, B., Holling, H., Çelik, P., Storme, M., and Lubart, T. (2017). Typing speed as a confounding variable and the measurement of quality in divergent thinking. Creat. Res. J. 29, 257-269. doi: 10.1080/10400419.2017.1360059

Forthmann, B., Szardenings, C., and Holling, H. (2018). Understanding the confounding effect of fluency in divergent thinking scores: revisiting average scores to quantify artifactual correlation. Psychol. Aesthet. Creat. Arts. Advanced online publication. doi: 10.1037/aca0000196

Frensch, P. A., and Sternberg, R. J. (1989). Expertise and intelligent thinking: when is it worse to know better. Adv. Psychol. Hum. Intell. 5, 157-188.

Funder, D. (2001). Personality. Annu. Rev. Psychol. 52, 197-221. doi: 10.1146/ annurev.psych.52.1.197

Gosling, S. D., Rentfrow, P. J., and Swann, W. B. (2003). A very brief measure of the big-five personality domains. J. Res. Pers. 37, 504-528. doi: 10.1016/ S0092-6566(03)00046-1

Griffin, W. G. (2008). From performance to mastery: developmental models of the creative process. J. Advert. 37, 95-108. doi: 10.2753/JOA0091-3367370408

Guilford, J. P. (1968). Creativity, intelligence and their educational implications. (San Diego, CA: EDITS/Knapp).

Hayes, A. F. (2009). Beyond Baron and Kenny: statistical mediation analysis in the new millennium. Commun. Monogr. 76, 408-420. doi: 10.1080/ 03637750903310360

Hocevar, D. (1981). Measurement of creativity: review and critique. J. Pers. Assess. 45, 450-464. doi: 10.1207/s15327752jpa4505_1

Holland, J. L. (1960). The prediction of college grades from personality and aptitude variables. J. Educ. Psychol. 51, 245-254. doi: 10.1037/h0041601

Hu, X., Erb, M., Ackermann, H., Martin, J. A., Grodd, W., and Reiterer, S. M. (2011). Voxel-based morphometry studies of personality: issue of statistical model specification-effect of nuisance covariates. NeuroImage 54, 1994-2005. doi: 10.1016/j.neuroimage.2010.10.024

Jauk, E., Benedek, M., and Neubauer, A. C. (2014). The road to creative achievement: a latent variable model of ability and personality predictors. Eur. J. Personal. 28, 95-105. doi: 10.1002/per.1941

Kaplan, D., and Depaoli, S. (2012). "Bayesian structural equation modeling" in Handbook of structural equation modeling. ed. R. Hoyle (New York, NY: Guilford Press), 650-673.

Kaufman, S. B. (2013). Opening up openness to experience: a four-factor model and relations to creative achievement in the arts and sciences. J. Creat. Behav. 47, 233-255. doi: 10.1002/jocb.33

Kilgour, M., and Koslow, S. (2009). Why and how do creative thinking techniques work?: trading off originality and appropriateness to make more creative advertising. J. Acad. Mark. Sci. 37, 298-309. doi: 10.1007/ s11747-009-0133-5

Koslow, S., Sasser, S. L., and Riordan, E. A. (2003). What is creative to whom and why? Perceptions in advertising agencies. J. Advert. Res. 43, 1-15. doi: 10.2501/jar-43-1-96-110

Lee, S. Y., and Song, X. Y. (2004). Evaluation of the Bayesian and maximum likelihood approaches in analyzing structural equation models with small sample sizes. Multivariate Behav. Res. 39, 653-686. doi: 10.1207/s15327906 mbr3904_4

Leung, A. K. Y., Maddux, W. W., Galinsky, A. D., and Chiu, C. Y. (2008). Multicultural experience enhances creativity: the when and how. Am. Psychol. 63, 169-181. doi: 10.1037/0003-066X.63.3.169 
Li, W., Li, X., Huang, L., Kong, X., Yang, W., Wei, D., et al. (2014). Brain structure links trait creativity to openness to experience. Soc. Cogn. Affect. Neurosci. 10, 191-198. doi: 10.1093/scan/nsu041

Lubart, T. I. (2001). Models of the creative process: past, present and future. Creat. Res. J. 13, 295-308. doi: 10.1207/S15326934CRJ1334_07

Maxwell, S. E., and Cole, D. A. (2007). Bias in cross-sectional analyses of longitudinal mediation. Psychol. Methods 12, 23-44. doi: 10.1037/1082-989X.12.1.23

McCaffrey, T. (2012). Innovation relies on the obscure: a key to overcoming the classic problem of functional fixedness. Psychol. Sci. 23, 215-218. doi: $10.1177 / 0956797611429580$

McCrae, R. R. (1987). Creativity, divergent thinking, and openness to experience. J. Pers. Soc. Psychol. 52, 1258-1265. doi: 10.1037/0022-3514.52.6.1258

Milgram, R. M., and Hong, E. (1999). Creative out-of-school activities in intellectually gifted adolescents as predictors of their life accomplishments in young adults: a longitudinal study. Creat. Res. J. 12, 77-88. doi: 10.1207/ s15326934crj1202_1

Mumford, M. D., Mobley, M. I., Reiter-Palmon, R., Uhlman, C. E., and Doares, L. M. (1991). Process analytic models of creative capacities. Creat. Res. J. 4, 91-122. doi: 10.1080/10400419109534380

Muthén, B., and Asparouhov, T. (2012). Bayesian structural equation modeling: a more flexible representation of substantive theory. Psychol. Methods 17, 313-335. doi: 10.1037/a0026802

Muthén, L. K., and Muthén, B. O. (2015). Mplus user's guide (version 7.4). (Los Angeles, CA: Muthén \& Muthén).

Nyilasy, G., and Reid, L. N. (2009). Agency practitioner theories of how advertising works. J. Advert. 38, 81-96. doi: 10.2753/JOA0091-3367380306

Paek, S. H., Park, H., Runco, M. A., and Choe, H. S. (2016). The contribution of ideational behavior to creative extracurricular activities. Creat. Res. J. 28, 144-148. doi: 10.1080/10400419.2016.1162547

Puryear, J. S., Kettler, T., and Rinn, A. N. (2017). Relationships of personality to differential conceptions of creativity: a systematic review. Psychol. Aesthet. Creat. Arts 11, 59-68. doi: 10.1037/aca0000079

Runco, M. A., and Acar, S. (2012). Divergent thinking as an indicator of creative potential. Creat. Res. J. 24, 66-75. doi: 10.1080/10400419.2012.652929

Runco, M. A., and Albert, R. S. (1985). The reliability and validity of ideational originality in the divergent thinking of academically gifted and nongifted children. Educ. Psychol. Meas. 45, 483-501. doi: 10.1177/001316448504500306

Runco, M. A., and Albert, R. S. (1986). The threshold hypothesis regarding creativity and intelligence: an empirical test with gifted and nongifted children. Creat. Child Adult Q. 11, 212-218.

Runco, M. A., Dow, G., and Smith, W. (2006). Information, experience, and divergent thinking: an empirical test. Creat. Res. J. 18, 269-277. doi: 10.1207/ s15326934crj1803_4

Runco, M. A., Illies, J. J., and Eisenman, R. (2005). Creativity, originality, and appropriateness: what do explicit instructions tell us about their relationships? J. Creat. Behav. 39, 137-148. doi: 10.1002/j.2162-6057.2005.tb01255.x

Runco, M. A., and Jaeger, G. J. (2012). The standard definition of creativity. Creat. Res. J. 24, 92-96. doi: 10.1080/10400419.2012.650092

Runco, M. A., Noble, E. P., and Luptak, Y. (1990). Agreement between mothers and sons on ratings of creative activity. Educ. Psychol. Meas. 50, 673-680. doi: 10.1177/0013164490503025

Sánchez-Ruiz, M. J., Hernández-Torrano, D., Pérez-González, J. C., Batey, M., and Petrides, K. V. (2011). The relationship between trait emotional intelligence and creativity across subject domains. Motiv. Emot. 35, 461-473. doi: 10.1007/ s11031-011-9227-8

Sasser, S. L., and Koslow, S. (2008a). The creative advertising development process: is organizational politics a recipe for disaster or a dysfunctional antidote? in New trends in advertising research. eds. F. C. Pereira, J. Veríssimo and P. C. Nijens (Lisbon, Portugal: Edições Sílabo), 103-119.

Sasser, S. L., and Koslow, S. (2008b). Desperately seeking advertising creativity: engaging an imaginative "3Ps" research agenda. J. Advert. 37, 5-20. doi: 10.2753/JOA0091-3367370401

Sasser, S. L., and Koslow, S. (2012). Passion, expertise, politics, and support. J. Advert. 41, 5-18. doi: 10.2753/JOA0091-3367410301
Schilling, M. A. (2005). A “small-world" network model of cognitive insight. Creat. Res. J. 17, 131-154. doi: 10.1207/s15326934crj1702\&3_2

Silvia, P. J., Nusbaum, E. C., Berg, C., Martin, C., and O'Connor, A. (2009). Openness to experience, plasticity, and creativity: exploring lower-order, high-order, and interactive effects. J. Res. Pers. 43, 1087-1090. doi: 10.1016/j. jrp.2009.04.015

Silvia, P. J., Wigert, B., Reiter-Palmon, R., and Kaufman, J. C. (2012). Assessing creativity with self-report scales: a review and empirical evaluation. Psychol. Aesthet. Creat. Arts 6, 19-34. doi: 10.1037/a0024071

Simonton, D. K. (1988). Scientific genius: A psychology of science. (Cambridge, MA: Cambridge University Press).

Simonton, D. K. (2003). "Expertise, competence, and creative ability: the perplexing complexities" in The psychology of abilities, competencies, and expertise. eds. R. J. Sternberg, and E. L. Grigorenko (Cambridge: Cambridge University Press), 213-239.

Simonton, D. K. (2012). Taking the US Patent Office criteria seriously: a quantitative three-criterion creativity definition and its implications. Creat. Res. J. 24, 97-106. doi: 10.1080/10400419.2012.676974

Simonton, D. K. (2018). Defining creativity: don't we also need to define what is not creative? J. Creat. Behav. 52, 80-90. doi: 10.1002/jocb.137

Smith, R. E., MacKenzie, S. B., Yang, X., Buchholz, L. M., and Darley, W. K. (2007). Modeling the determinants and effects of creativity in advertising. Mark. Sci. 26, 819-833. doi: 10.1287/mksc.1070.0272

Smith, R. E., and Yang, X. (2004). Toward a general theory of creativity in advertising: examining the role of divergence. Mark. Theory 4, 31-58. doi: $10.1177 / 1470593104044086$

Stenling, A., Ivarsson, A., Johnson, U., and Lindwall, M. (2015). Bayesian structural equation modeling in sport and exercise psychology. J. Sport Exerc. Psychol. 37, 410-420. doi: 10.1123/jsep.2014-0330

Sternberg, R. J., and Lubart, T. I. (1996). Investing in creativity. Am. Psychol. 51, 677-688. doi: 10.1037/0003-066X.51.7.677

Taki, Y., Thyreau, B., Kinomura, S., Sato, K., Goto, R., Wu, K., et al. (2013). A longitudinal study of the relationship between personality traits and the annual rate of volume changes in regional gray matter in healthy adults. Hum. Brain Mapp. 34, 3347-3353. doi: 10.1002/hbm.22145

Taylor, A., and Greve, H. R. (2006). Superman or the fantastic four? Knowledge combination and experience in innovation teams. Acad. Manag. J. 49, 723-740. doi: 10.5465/amj.2006.22083029

Tiwana, A., and McLean, E. R. (2005). Expertise integration and creativity in information systems development. J. Manag. Inf. Syst. 22, 13-43. doi: 10.1080/07421222.2003.11045836

Vanden Bergh, B. G., Reid, L. N., and Schorin, G. A. (1983). How many creative alternatives to generate? J. Advert. 12, 46-49. doi: 10.1080/00913367. 1983.10672863

Wallach, M. A., and Kogan, N. (1965). Modes of thinking in young children. (New York: Holt, Rinehart, \& Winston).

Wallach, M. A., and Wing, C. W. Jr. (1969). The talented student; A validation of the creativity-intelligence distinction. New York: Holt, Rinehart and Winston.

Wiley, J. (1998). Expertise as mental set: the effects of domain knowledge in creative problem solving. Mem. Cogn. 26, 716-730. doi: 10.3758/BF03211392

Wilson, R. C., Guilford, J. P., and Christensen, P. R. (1953). The measurement of individual differences in originality. Psychol. Bull. 50, 362-370. doi: 10.1037/ h0060857

Conflict of Interest Statement: The authors declare that the research was conducted in the absence of any commercial or financial relationships that could be construed as a potential conflict of interest.

Copyright (C) 2019 Agnoli, Mastria, Kirsch and Corazza. This is an open-access article distributed under the terms of the Creative Commons Attribution License (CC BY). The use, distribution or reproduction in other forums is permitted, provided the original author(s) and the copyright owner(s) are credited and that the original publication in this journal is cited, in accordance with accepted academic practice. No use, distribution or reproduction is permitted which does not comply with these terms. 